\title{
Bonding of dental porcelain to non-cast titanium with different surface treatments
}

\author{
Mau-Chin LIN ${ }^{1,2}$, Kuo-Lung TUNG ${ }^{3}$, Sheng-Chieh LIN³ and Her-Hsiung HUANG $2,4,5$ \\ ${ }^{1}$ Department of Dental Technology and Materials Science, Central Taiwan University of Science and Technology, Taichung 406, Taiwan \\ ${ }^{2}$ Department of Dentistry, National Yang-Ming University, Taipei 112, Taiwan \\ ${ }^{3}$ Department of Dental Laboratory Technology, Shu-Zen College of Medicine and Management, Kaohsiung 821, Taiwan \\ ${ }^{4}$ Department of Dentistry, Taipei City Hospital, Taipei 115, Taiwan \\ ${ }^{5}$ Department of Stomatology, Taipei Veterans General Hospital, Taipei 112, Taiwan \\ Corresponding author, Her-Hsiung HUANG; E-mail: hhhuang@ym.edu.tw, Sheng-Chieh LIN; sllin@ms.szmc.edu.tw
}

\begin{abstract}
This study investigated the bonding of dental porcelain to non-cast Ti surface with different treatments. Mechanically ground noncast Ti strips, simulating surface conditions produced by CAD/CAM, were $\mathrm{Al}_{2} \mathrm{O}_{3}$-sandblasted, then subjected to different surface treatments, including immersion in $\mathrm{HNO}_{3}$-containing acid, $\mathrm{NaOH}$-containing alkaline, and $\mathrm{NaOH}$-containing alkaline then $\mathrm{HNO}_{3}$ containing acid. Ti-porcelain specimens preparations and their bend strength measurements were based on ISO 9693. Ti surface treatment changed not only surface roughness but also surface chemistry, leading to influence on bond strength. Bond strengths of all Ti-porcelain groups were higher than ISO 9693 minimum requirement. The sandblasted/acid-treated Ti surface showed the highest bond strength (34.60 MPa) with porcelain; no significant difference in bond strength (27.92-29.63 MPa) was found among other Tiporcelain groups. All Ti-porcelain specimens showed adhesive bond failure. Bonding between non-cast Ti and dental porcelain was strengthened by a simple and practical sandblasting/acid-etching treatment of the Ti surface prior to porcelain sintering.
\end{abstract}

Keywords: Surface treatment, Non-cast titanium, Dental porcelain, Bond strength

\section{INTRODUCTION}

Titanium (Ti) tends to react with oxygen at high temperatures, which results in an overly thick oxidization layer. The oxidization layer is located on the Ti surface and influences the bond strength of the Ti-porcelain prosthetic appliance ${ }^{1,2)}$. It has been reported that dental porcelain-fused-to-metal (PFM) crowns can be produced with a thinner interfacial oxide layer that effectively promotes the bond between metal and porcelain ${ }^{3}$. Thus, several manufacturers have produced low-fusing dental porcelain that is suitable for sintering onto the $\mathrm{Ti}$ surfaces with thinner oxide layers ${ }^{4}$. However, the bond strength between low-temperature porcelain and $\mathrm{Ti}$ is only slightly higher than the minimum metal-porcelain bond strength prescribed by ISO $9693^{5}$. Relevant literature shows that the Ti-porcelain bond strength is still lower than the bond strength between porcelain and other noble or base metals ${ }^{6,7}$. Consequently, there is a need for further investigation to improve the Ti-porcelain bond strength, which may be applicable to PFM dental crowns for long-term clinical application.

The strength of the bond between metal and porcelain can be influenced by several factors, including the metal and porcelain chemical compositions, metal surface treatment, porcelain sintering procedure and test method ${ }^{8}$. The bond strength primarily depends on the mechanical and chemical properties of the interface between the metal and porcelain ${ }^{9,10}$. Although extensive studies have employed different surface treatments of $\mathrm{Ti}$ prior to porcelain sintering ${ }^{11-19)}$, a simple and practical technique to improve Ti-porcelain bond strength has not been well determined, and the underlying mechanism for the bonding of Ti and porcelain is not well understood.

Chemical solution treatment is a method that can be used to treat and clean metallic surfaces for clinical applications ${ }^{20)}$. In industrial fields, an alkaline or acid solution has been successfully employed to clear superficial pollutants from $\mathrm{Ti}$ and $\mathrm{Ti}$ alloys ${ }^{21}$. Diniz et $a l .{ }^{22)}$ indicated that hydrofluoric acid can serve as an improvement agent and etchant of $\mathrm{Ti}$, thus allowing a higher-quality metallic surface and the removal of pollutants produced during manufacturing. A previous study showed that the Ti surface hardness increases after immersion in a mixed nitric acid/hydrofluoric acid solution such that the Ti-porcelain bond strength is improved ${ }^{23}$. Reyes et al. ${ }^{8)}$ found that the bonding of $\mathrm{Ti}$ and porcelain can be improved by immersing the $\mathrm{Ti}$ in hydrochloric acid prior to porcelain sintering. Tróia et al. ${ }^{12)}$ studied the bond strength between porcelain and cast $\mathrm{Ti}$ with different surface chemical treatments. The Ti surface is immersed in acid solution, treated (or not treated) with alkaline solution, and finally sandblasted prior to porcelain sintering. There is no improvement in the Ti-porcelain bond strength when the Ti surface is only immersed in acid solution. The bond strength is enhanced when the Ti surface is first treated with an acid solution followed by an alkaline solution treatment, with a sandblast treatment as the final step. However, from a dental technician point of view, it should be noted that the sandblasting process is usually employed as the first treatment step for metallic prosthetic cast appliances following the casting process.

One of the problems for dental $\mathrm{Ti}$ cast made by 
conventional lost-wax technique is the presence of a hardened alpha-case surface layer with a thickness of tens to few hundreds $\mu \mathrm{m}^{24,25}$. The alpha-case surface layer on $\mathrm{Ti}$ cast has much higher hardness than the internal structure. Therefore, the hardened alphacase layer can hinder the grinding and polishing of Ti cast prostheses and is easy for crack initiation and propagation $^{26)}$. Recently, computer-aided design (CAD)/ computer-assisted manufacturing (CAM) has been clinically used to produce high-quality $\mathrm{Ti}$ prosthetic appliances ${ }^{27)}$. Through CAD/CAM procedures, Ti for fixed prosthetic appliances (dental crowns and copings) can be produced without the generation of a thick oxide layer on the Ti surface; this leaves a more homogeneous surface structure ${ }^{28}$. The CAD/CAM-produced Ti surface is expected to have greater porcelain bond strength than the traditional Ti surface produced by the casting process $^{29,30)}$. The bond strength of porcelain to the CAD/ CAM-produced non-cast Ti surface is becoming more important in dentistry.

Although some researches have focused on the bonding properties between the porcelain and noncast $\mathrm{Ti}$ surfaces without surface treatments ${ }^{6,31-33)}$, the mechanism of the bonding behavior is still not well understood. Previous studies seldom discussed the influence of chemical solutions on the bond strength between porcelain and non-cast Ti surfaces produced by CAD/CAM. The prevailing hypothesis is that the mechanical and chemical treatments of non-cast $\mathrm{Ti}$ surfaces prior to porcelain sintering can positively affect Ti-porcelain bond strength. The objective of this study was to determine a simple and practical procedure involving mechanical (e.g., sandblasting) and chemical (e.g., acid and/or caustic alkaline solution) treatments to increase the bond strength between the porcelain and non-cast Ti surface interface simulating CAD/CAM conditions.

\section{MATERIALS AND METHODS}

\section{Specimen preparation}

Commercially pure non-cast $\mathrm{Ti}$ strips (Grade $2 \mathrm{Ti}$, Ultimate Materials Technology Co., Hsinchu, Taiwan) after annealing treatment were used as test specimens; these were mechanically ground with silicon carbide paper to \#240 (WTCC-S, Nihonkenshi Co, Osaka, Japan). The spontaneously formed surface thin oxide film, mainly as $\mathrm{TiO}_{2}$, on the ground, non-cast Ti strips was close to $10 \mathrm{~nm}$, which was identified by X-ray photoelectron spectroscopy depth profile analysis (not shown here). The final test Ti strips had a size of $25 \mathrm{~mm} \times 3 \mathrm{~mm} \times 0.5 \mathrm{~mm}$, which was confirmed using a digital caliper (Micrometer 193, Mitutoyo, Kawasaki, Japan). The ground, noncast $\mathrm{Ti}$ surface without a thick hardened alpha-case layer simulated the surface conditions produced using the CAD/CAM milling process. The surface roughness $\left(R_{a}\right)$ of the ground, non-cast Ti strip was $0.36 \mu \mathrm{m}$ which was nearly the same as that of the Ti strip produced by commercial CAD/CAM milling system (DATRON D5, Datron Dynamics, Inc., Milford, USA). Forty Ti strips were then divided into four groups (ten samples each) for the following surface treatments. The Ti strips sandblasted with $125 \mu \mathrm{m} \mathrm{Al}_{2} \mathrm{O}_{3}$ particles (WA, Rich Sou Technology Co., Kaohsiung, Taiwan) at a 4-bar pressure for $10 \mathrm{~s}$ in a sandblaster (BL-22, Fu Ming Co., Taichung, Taiwan) were used as the control (group SB), and the remaining three groups were experimental groups that were described as follows: for group SB-A, the SB specimens were immersed in an acid $\left(35 \% \mathrm{HNO}_{3}+5 \% \mathrm{HF}\right)$ solution; for group SB-C, the SB specimens were immersed in a caustic alkaline $(50 \% \mathrm{NaOH})$ solution; and for group SB-CA, the SB specimens were immersed in a caustic alkaline solution followed by an acid solution. All chemical reagents were from Merck Chemicals (Merck KGaA, Darmstadt, Germany). The detailed steps for the surface treatments of Ti strips are shown in Table 1.

According to ISO 9693 specification $^{5}$ ), a low-fusing porcelain (Vita Titankeramik, Vita, Bad Säckingen, Germany) was sintered on the center of the Ti strips of size $8 \mathrm{~mm} \times 3 \mathrm{~mm} \times 1 \mathrm{~mm}$. In accordance with the sintering conditions recommended by the manufacturer (Table 2), as well as the actual operating sequence in the dental technology laboratory, the following porcelain sintering procedures were used: a thin $(<0.1$ $\mathrm{mm}$ ) porcelain bond layer was first sintered on the $\mathrm{Ti}$ strips, followed by the sintering of opaque porcelain approximately $0.2 \mathrm{~mm}$ thick; the final sintering of dentin porcelain was approximately $0.8 \mathrm{~mm}$ thick. The porcelain layers (opaque and dentin) were applied with two different custom-made jigs which controlled the position and thickness of each. At the end, a glazing treatment was performed. The sintering processes were conducted in a dental vacuum porcelain furnace (Pro 100, Whipmix, Louisville, USA).

\section{Bond strength of Ti-porcelain specimens}

A universal test machine (EZ-L, Shimadzu, Tokyo, Japan) was used for the three-point bending test of the Ti-porcelain strip specimens according to the ISO 9693 specification. During the bending test, the porcelain surface faced downwards, and the load was applied to the center of the Ti surface at a rate of $0.5 \mathrm{~mm} / \mathrm{min}$. The in situ load $v$ s displacement curves were recorded during the bending tests. The fracture load (or debonding load) was measured for specimens failing by a debonding crack occurring at one end of the porcelain layer ${ }^{5)}$. The Ti-porcelain bond strength was then calculated with the following equation provided by ISO $9693^{5}$ :

\section{Bond strength $=\mathrm{F} \times \mathrm{k}$}

where $\mathrm{F}$ is the fracture load; the coefficient $\mathrm{k}$ is a function of the thickness and elastic modulus of Ti strip according to ISO 9693 specification. The elastic modulus of Ti strip in bending test was determined according to the following equation ${ }^{34)}$ :

\section{$\mathrm{E}=\mathrm{L}^{3} \Delta \mathrm{P} / 4 \mathrm{bh}{ }^{3} \Delta \mathrm{d}$}

where $\mathrm{E}$ is the elastic modulus of Ti strip in bending, $\mathrm{L}$ 
Table 1 Steps of surface treatments for Ti strips used in this study

\begin{tabular}{|c|c|}
\hline Group & Description of surface treatment procedures \\
\hline $\mathrm{SB}$ & $\begin{array}{l}\text { Step 1: Sandblasting with } 125 \mu \mathrm{m} \mathrm{Al}_{2} \mathrm{O}_{3} \text { particles } \\
\text { Step 2: Ultrasonic cleaning in distilled water for } 3 \mathrm{~min}\end{array}$ \\
\hline SB-A & $\begin{array}{l}\text { Step 1: Sandblasting with } 125 \mu \mathrm{m} \mathrm{Al}_{2} \mathrm{O}_{3} \text { particles } \\
\text { Step 2: Immersion in } 35 \% \mathrm{HNO}_{3}+5 \% \mathrm{HF} \text { containing acid solution for } 3 \mathrm{~min} \\
\text { Step 3: Ultrasonic cleaning with distilled water for } 3 \mathrm{~min}\end{array}$ \\
\hline SB-C & $\begin{array}{l}\text { Step 1: Sandblasting with } 125 \mu \mathrm{m} \mathrm{Al}_{2} \mathrm{O}_{3} \text { particles } \\
\text { Step 2: Immersion in } 50 \% \mathrm{NaOH} \text {-containing caustic alkaline solution for } 5 \mathrm{~min} \\
\text { Step 3: Ultrasonic cleaning with distilled water for } 3 \mathrm{~min}\end{array}$ \\
\hline SB-CA & $\begin{array}{l}\text { Step 1: Sand blasting with } 125 \mu \mathrm{m} \mathrm{Al}_{2} \mathrm{O}_{3} \text { particles } \\
\text { Step 2: Immersion in } 50 \% \mathrm{NaOH} \text {-containing caustic alkaline solution for } 5 \mathrm{~min} \\
\text { Step 3: Immersion in } 35 \% \mathrm{HNO}_{3}+5 \% \mathrm{HF} \text { containing acid solution for } 3 \mathrm{~min} \\
\text { Step 4: Ultrasonic cleaning with distilled water for } 3 \mathrm{~min}\end{array}$ \\
\hline
\end{tabular}

Table 2 Porcelain sintering procedure conditions recommended by the manufacturer

\begin{tabular}{|c|c|c|c|c|c|}
\hline Step & $\begin{array}{l}\text { Initial temp. } \\
\qquad\left({ }^{\circ} \mathrm{C}\right)\end{array}$ & $\begin{array}{l}\text { Final temp. } \\
\qquad\left({ }^{\circ} \mathrm{C}\right)\end{array}$ & $\begin{array}{l}\text { Temp. rising rate } \\
\left({ }^{\circ} \mathrm{C} / \mathrm{min}\right)\end{array}$ & $\begin{array}{l}\text { Holding time } \\
\qquad(\min )\end{array}$ & $\begin{array}{c}\text { Vacuum degree } \\
\text { (bar) }\end{array}$ \\
\hline 1. Bonder & 400 & 800 & 60 & 1 & 6 \\
\hline 2. Opaque & 400 & 790 & 110 & 1 & 4 \\
\hline 3. First dentin & 400 & 770 & 50 & 1 & 8 \\
\hline 4. Second dentin & 400 & 770 & 50 & 1 & 8 \\
\hline 5. Glazing & 400 & 770 & 100 & 1 & 4 \\
\hline
\end{tabular}

is the distance between two supporting points $(20 \mathrm{~mm})$ for the Ti strip, b is the Ti strip width $(3 \mathrm{~mm}), \mathrm{h}$ is the Ti strip thickness $(0.5 \mathrm{~mm})$, and $\Delta \mathrm{P}$ and $\Delta \mathrm{d}$ are the load and displacement increments, respectively.

\section{Surface characterizations}

After Ti strips underwent different surface treatments, X-ray photoelectron spectrometry (XPS) (Sigma Probe, Thermo VG Scientific Inc., West Sussex, UK) was used to analyze the surface chemical compositions of the $\mathrm{Ti}$ strips prior to porcelain sintering. Scanning electron microscopy (SEM) (JSM-6500F, JEOL Ltd., Tokyo, Japan) was used to observe the surface morphology of the Ti strips before porcelain sintering and the interfacial cross section between the porcelain and Ti after porcelain sintering. The surface arithmetic mean roughness $R_{a}$ of Ti strips after surface treatments was measured using a surface profilometer (Dektak 3, Veeco Instruments Inc., NY, USA). After three-point bending tests, the fracture surfaces of the $\mathrm{Ti}$ and porcelain sides of the tested Ti-porcelain specimens were analyzed using SEM accompanied by energy dispersive spectrometry (EDS) (INCA Energy 300, Oxford Instruments, Oxfordshire, UK) to observe the surface topography and to analyze the surface chemical composition.

\section{Statistical analysis}

For the statistical analysis, a one-way analysis of variance (ANOVA) was used to analyze whether different surface treatment methods affect the surface roughness and Ti-porcelain bond strength. A $p<0.05$ was considered to be statistically significant in all tests. Tukey's test was used as the post-hoc test. Ten samples were used in each test group.

\section{RESULTS}

After the grinding, the non-cast Ti strips underwent the different surface treatments shown in Table 1. The corresponding surface topography and surface roughness were shown in Fig. 1: (a) SEM micrographs; (b) surface roughness $R_{a}$ (mean \pm standard deviation). Figure 1(a) shows a rough and sharp surface pattern that was produced on the group SB surface. The group SB surfaces were cleaned by immersion in caustic alkaline solution and/or acid solution, and the surface of the chemically treated Ti strips (groups SB-A, SB-C and SB-CA) visibly exhibited a different color. As shown in Fig. 1(b), the groups SB-A $\left(R_{\mathrm{a}}: 0.718 \pm 0.069 \mu \mathrm{m}\right)$ and SB-C $\left(R_{\mathrm{a}}: 0.703 \pm 0.078 \mu \mathrm{m}\right)$ had a significantly lower surface roughness than the control group $\mathrm{SB}\left(\mathrm{R}_{\mathrm{a}}: 1.048 \pm 0.042\right.$ $\mu \mathrm{m})\left({ }^{* * *}: p<0.001\right)$; there was no significant difference in 

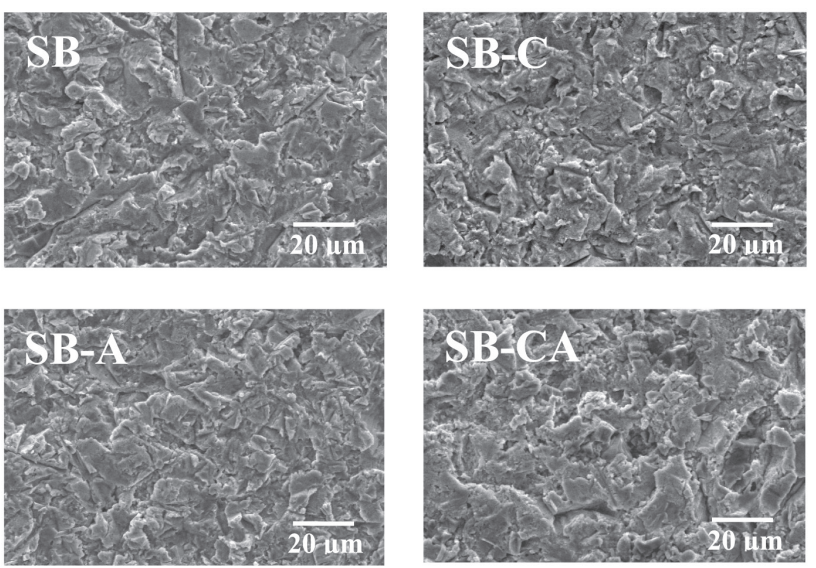

(a)

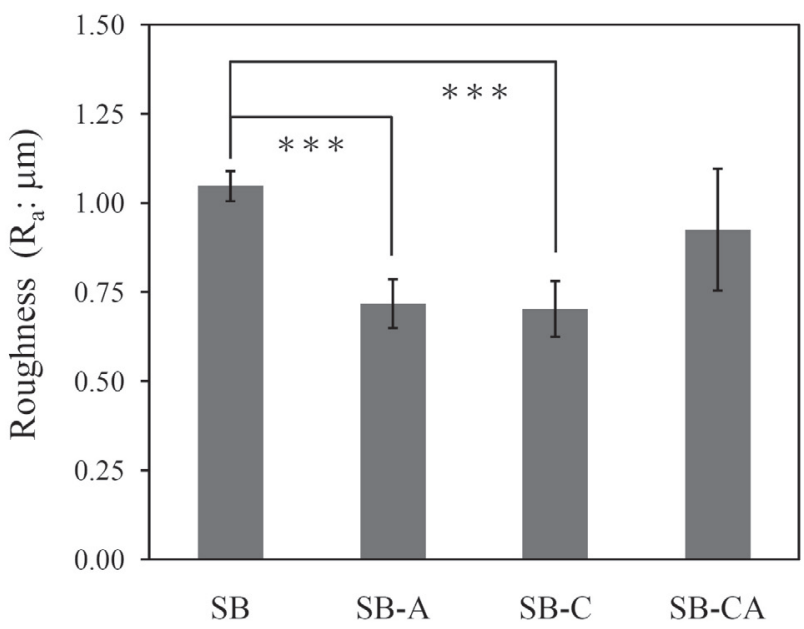

(b)

Fig. 1 (a) scanning electron microscope micrographs and (b) surface roughnesses $R_{a}$ of the non-cast Ti strips after the different surface treatments described in Table 1 (error bar represented standard deviation; $* * *: p<0.001)$.

$\mathrm{R}_{\mathrm{a}}$ between groups $\mathrm{SB}$ and SB-CA.

Figure 2 shows the XPS chemical analysis results of $\mathrm{Ti} 2 \mathrm{p}_{3}$ spectra, corresponding to $\mathrm{TiO}_{2}$, on the outermost surface of non-cast Ti strips after the different surface treatments. The surface treatment appeared to have an influence on the surface chemistry of the Ti strips prior to porcelain sintering. Among the test groups, SB-A specimens showed the least amount of residual $\mathrm{Ti}_{2} \mathrm{p}_{3}$ on the outermost surface of the Ti strip; the surfaces of SB-C and SB-CA specimens showed a greater amount of residual $\mathrm{Ti}_{2} \mathrm{p}_{3}$ than the $\mathrm{SB}-\mathrm{A}$ and $\mathrm{SB}$ specimens.

Figure 3 shows the SEM observations of the interfacial cross section of the Ti-porcelain specimens with different surface treatments: higher magnifications of (a) (as indicated by arrows) were shown in (b). The Ti-porcelain interface of the SB-C, SB-A and SB-CA

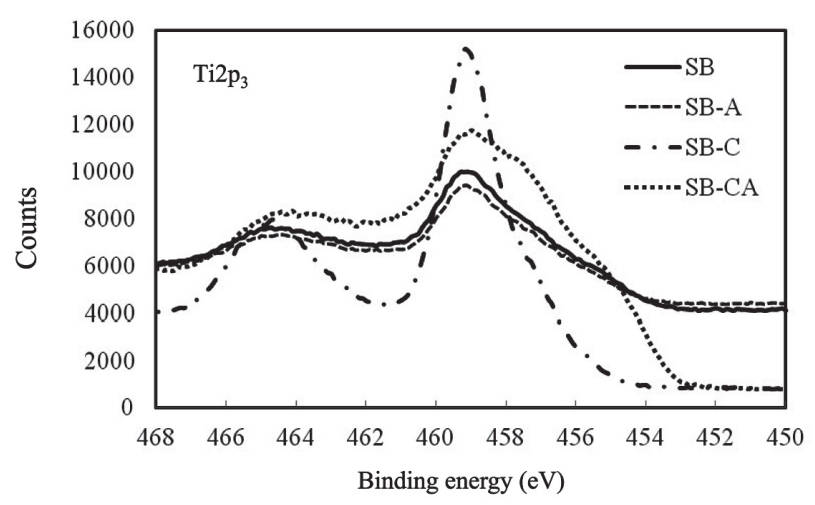

Fig. 2 X-ray photoelectron spectroscopy analysis of superficial $\mathrm{Ti}_{2} \mathrm{p}_{3}$ spectra, corresponding to $\mathrm{TiO}_{2}$, on the non-cast Ti strips after the different surface treatments described in Table 1.

experimental groups was smoother than that of the SB control group.

The Ti-porcelain bond strengths of the various test groups in the three-point bending tests are shown in Table 3. The one-way ANOVA analysis results showed that only the acid treatment for the group SB surface before porcelain sintering had a significant influence on the bond strength of the Ti-porcelain specimens $(p<0.01)$. The SB-A specimens exhibited the maximum bond strength (34.60 MPa); the SB, SB-C and SB-CA specimens had bond strengths ranging from 27.92 to 29.63 MPa. The Tukey's post-hoc tests showed that no significant difference existed among the SB, SB-C and SB-CA test groups.

Figures 4 and 5 show the results of the SEM observation and EDS mapping analysis ( $\mathrm{Si}$ and $\mathrm{Ti}$ elements) of the $\mathrm{Ti}$ and porcelain sides, respectively, of the fracture surface of the SB-A specimens after the three-point bending test. After the bending test, the Si and $\mathrm{Ti}$ elements were observed on the $\mathrm{Ti}$ and porcelain sides, respectively, of the fracture surface. The same results were also observed for the other three test groups, indicating that the Ti metal side of the fracture surface of the Ti-porcelain specimens after the bending tests had residual porcelain, and the porcelain side had residual Ti metal.

\section{DISCUSSION}

The experimental results conditionally supported our research hypothesis that the combined mechanical/ chemical treatments of the ground, non-cast $\mathrm{Ti}$ surfaces can improve the bond strength between $\mathrm{Ti}$ and porcelain prior to porcelain sintering. Compared with the control group SB (bond strength 29.63 MPa), a sandblasting treatment followed by immersion in a $\mathrm{HNO}_{3}$-containing acid solution to treat ground, non-cast Ti surface (group SB-A) before porcelain sintering can significantly improve the bond strength of Ti-porcelain specimens (bond strength $34.60 \mathrm{MPa})(p<0.01)$. However, 


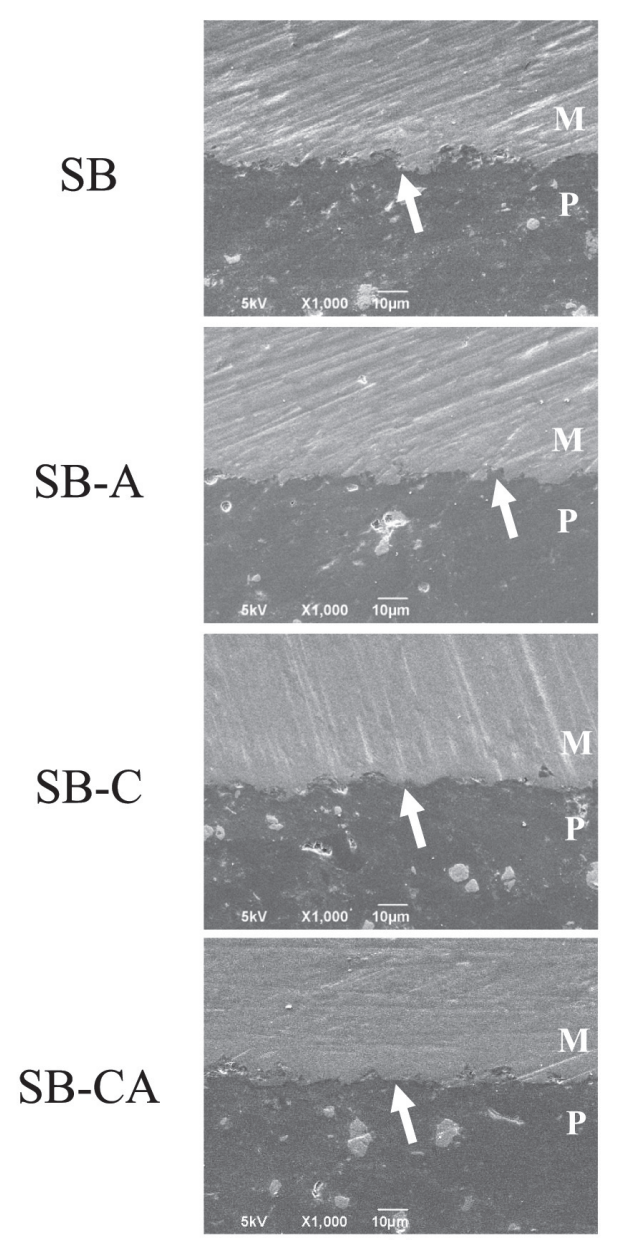

(a)
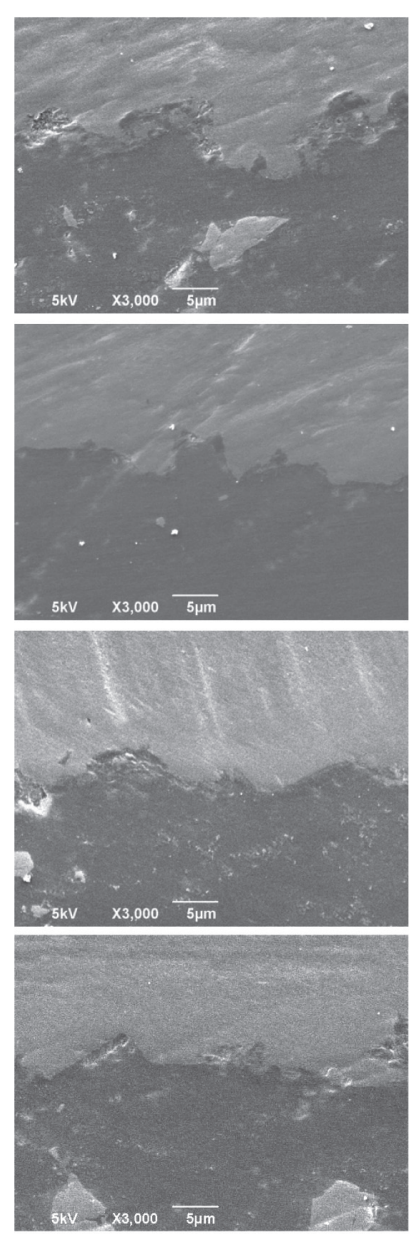

(b)

Fig. 3 Scanning electron microscopy of the interfacial cross section of Ti-porcelain specimens (M: Ti metal, P: porcelain; higher magnifications of (a) (as indicated by arrows) were shown in (b)).

Table 3 Means and standard deviations of bond strengths of Ti-porcelain strip specimens after three-point bending tests (note: mean values with different letters were significantly different $(p<0.01))$

\begin{tabular}{lc}
\hline Group & Mean \pm SD $(\mathrm{MPa})$ \\
\hline SB & $29.63 \pm 1.14^{\mathrm{a}}$ \\
SB-A & $34.60 \pm 1.79^{\mathrm{b}}$ \\
SB-C & $28.43 \pm 2.23^{\mathrm{a}}$ \\
SB-CA & $27.92 \pm 1.34^{\mathrm{a}}$ \\
\hline
\end{tabular}

sandblasting treatment followed by chemical immersion in $\mathrm{NaOH}$-containing solution (group $\mathrm{SB}-\mathrm{C}$ ) or $\mathrm{NaOH}$ containing solution and then in $\mathrm{HNO}_{3}$-containing acid solution (group SB-CA) as the surface treatments for ground, non-cast $\mathrm{Ti}$ metal cannot improve the bond strength of the Ti-porcelain specimens. It should be noted that regardless of the surface treatments, the bond strengths of all test groups were higher than 25 $\mathrm{MPa}$, which was the minimum value suggested by the ISO 9693 specification ${ }^{5}$.

Previous studies ${ }^{4,20)}$ have pointed out that the rough, cast Ti surface provides an important characteristic that increases Ti-porcelain bond strength. Different surface treatments for Ti produce dissimilar surface roughness, which may positively affect the mechanical bond properties between $\mathrm{Ti}$ and porcelain ${ }^{35,36)}$. In this study, the SEM observations show that mechanical sandblasting produced rough and irregular Ti surfaces (Fig. 1). The irregular and acute angles on the non-cast Ti surfaces produced during the sandblasting treatment were corroded (or smoothened) by chemical treatments in acid and/or caustic alkaline solutions. However, the bond strength of the experimental groups SB-C, SB-A and SB-CA with smoother surfaces was not statistically reduced when compared with the control group SB 

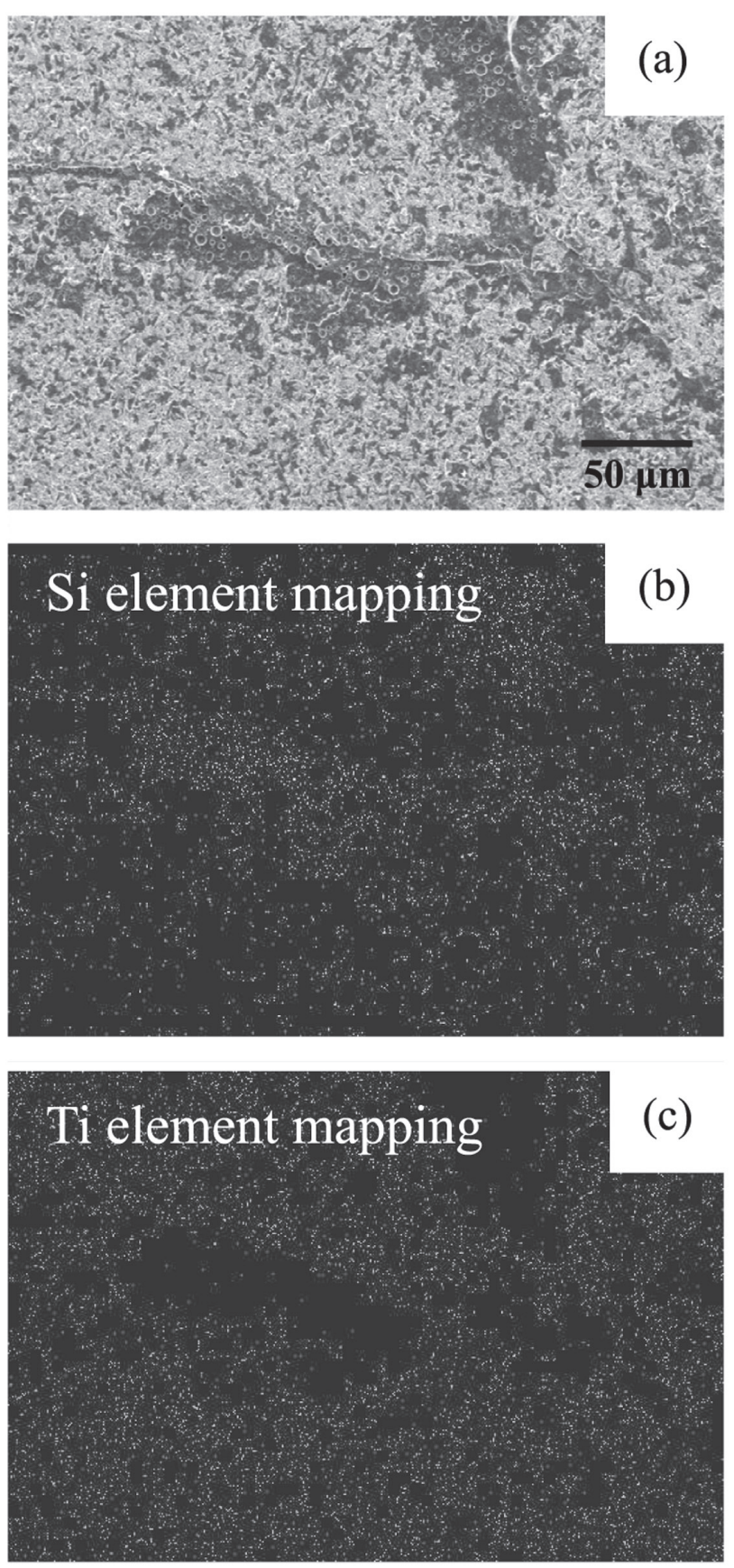

Fig. 4 Scanning electron microscope observation and energy dispersive spectrometer mapping analysis ( $\mathrm{Si}$ and $\mathrm{Ti}$ elements) of the metal side of the fracture surface of Ti-porcelain specimens (group SB-A) after the three-point bending test.

with rougher surfaces, which implies that a decrease in the surface roughness of the non-cast Ti might not significantly affect the bond strength between Ti and porcelain. In the present investigation, the surface treatments changed not only the Ti surface roughness (Fig. 1) but also the Ti surface chemistry (Fig. 2), which
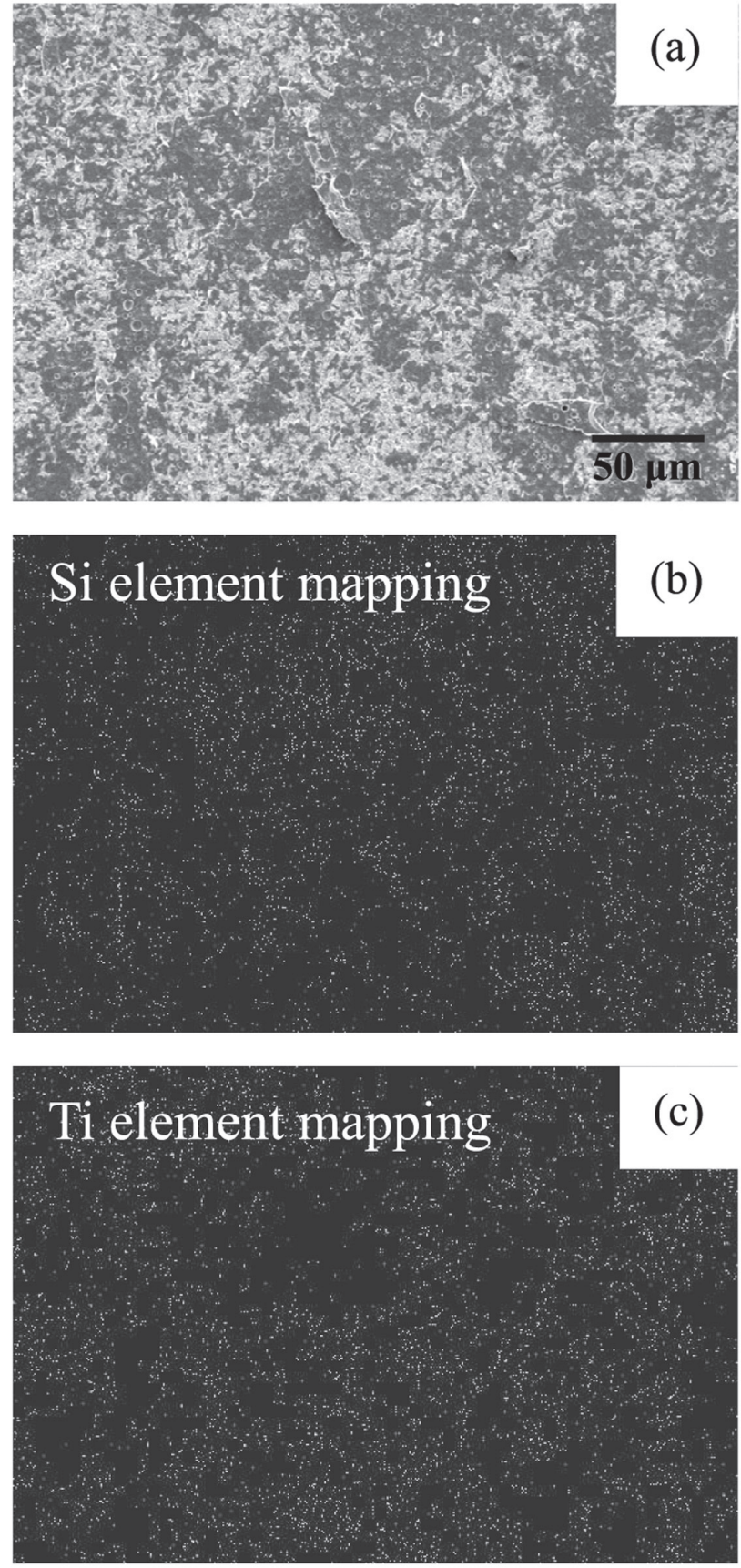

Fig. 5 Scanning electron microscope observation and energy dispersive spectrometer mapping analysis (Si and Ti elements) of the porcelain side of the fracture surface of Ti-porcelain specimens (group SB-A) after the three-point bending test.

might also play a role in the Ti-porcelain bond strength.

Cai et $a .^{23)}$ used EDS to analyze the chemical compositions of the cast Ti surface after chemical solution treatments. The residual metallic chemicals (e.g., Al and $\mathrm{Zr}$ ) on the cast $\mathrm{Ti}$ after the surface treatments might increase the Ti-porcelain bond strength. In this study, 
the SB-A specimens showed the least residual amount of $\mathrm{Ti}_{2} \mathrm{p}_{3}$ (corresponding to $\mathrm{TiO}_{2}$ ) on the non-cast Ti surface before porcelain sintering (Fig. 2), which indicates that the $\mathrm{HNO}_{3}$-containing acid solution may thin and clean the surface $\mathrm{Ti}$ oxides (mainly as $\mathrm{TiO}_{2}$ ) on the non-cast Ti before porcelain sintering and then increase the Tiporcelain bond strength after porcelain sintering.

The EDS analysis results in Figs. 4 and 5 show that the Ti side of the fracture surface of the SB-A specimens exhibited the residual Si element derived from the sintering porcelain side; the porcelain side of the fracture surface revealed the existence of the Ti element derived from the Ti metal side. Similar results were also observed for the other test group specimens (SB, SB-C and SB-CA). This implies that the fracture mode of the Ti-porcelain specimen during the bending test was an adhesive bond failure; the interface between the noncast Ti and porcelain had proper bond characteristics. Kimura et al. ${ }^{1)}$ noted that a thick (approximately $5 \mu \mathrm{m}$ ) metallic oxidization layer created on a pure Ti surface cannot effectively adhere to Ti; thus, the Ti-porcelain bond failure occurs in the oxide layer. In this study, the sintering temperature of the low-fusing porcelain used in this research was lower than $800^{\circ} \mathrm{C}$, which can inhibit the thickening of the oxide layer on the Ti surface during the porcelain sintering process ${ }^{37)}$. Moreover, the ground non-cast Ti surface was roughened and cleaned using sandblasting and chemical solution treatments, respectively, prior to porcelain sintering. The abovementioned factors may significantly improve the bond property between the non-cast Ti and porcelain (e.g. group SB-A). Thus, the fracture mode between the lowfusing porcelain and the surface-treated Ti appeared to be of an adhesive type for all test Ti-porcelain specimens. Moreover, the bond strengths of all test specimens were higher than the minimum value (25 MPa) suggested in the ISO 9693 specification.

It should be noted that the metallographical grinding/ polishing process, instead of the sandblasting process with $\mathrm{Al}_{2} \mathrm{O}_{3}$ particles, is used for Ti surface preparation prior to porcelain sintering in order to avoid the surface contamination of $\mathrm{Al}_{2} \mathrm{O}_{3}$ particles on the sandblasted $\mathrm{Ti}$ surface $^{38)}$. However, according to the manufacturer's advice, the sandblasting treatment with $\mathrm{Al}_{2} \mathrm{O}_{3}$ particles is usually employed as the first treatment step for $\mathrm{Ti}$ surface before porcelain sintering. In this study, based on the EDS analysis results, no significant contamination of $\mathrm{Al}_{2} \mathrm{O}_{3}$ particles was observed on the $\mathrm{SB}$ specimen surface which also showed a good bonding to porcelain (bond strength 29.63 MPa in Table 3).

For the ground, non-cast $\mathrm{Ti}$ surface without a hardened alpha-case layer, which simulated the surface conditions generated by the CAD/CAM procedure, the mechanical sandblasting treatment combined with the sequential chemical etching treatment using an $\mathrm{HNO}_{3}$ containing solution (group SB-A) significantly improved the Ti-porcelain bond strength as compared to the sandblasting treatment only (group SB). To increase the bond strength of the Ti-porcelain prosthetic appliance, it is simple and practical for dental technicians to apply the sandblasting treatment first and then use the acid etching solution to treat the Ti surface prior to porcelain sintering. Although previous studies have suggested that the surface ceramic coatings (e.g. $\mathrm{SiO}_{2}{ }^{15}$ ), $\mathrm{TiO}_{2}{ }^{16)}$, $\mathrm{NbN}^{17)}$ and $\mathrm{ZrN}^{17,18)}$ ) may significantly improve the cast Ti-porcelain bond strength $(>38 \mathrm{MPa})$. On the other hand, some reports have shown that the surface modifications (e.g. electrical discharge machining ${ }^{11)}, \mathrm{SnO}_{\mathrm{x}}$ coating ${ }^{13)}$, $\mathrm{ZrO}_{2}-\mathrm{Y}_{2} \mathrm{O}_{3}-\mathrm{MgO}$ coating ${ }^{14)}$ and $\mathrm{SiO}_{2}$ coating ${ }^{19)}$ ) on cast $\mathrm{Ti}$ surface increase the Ti-porcelain bond strengths $(<29$ $\mathrm{MPa}$ ) only a little higher than the minimum value (25 $\mathrm{MPa}$ ) suggested by ISO 9693. The abovementioned surface treatments are rather complicated and more expensive than the proposed treatment in this study. Besides, no further information on the surface treatment for the CAD/CAM-produced non-cast $\mathrm{Ti}$ has been reported. Obviously, in this study, a simple and practical treatment combining sandblasting/acid solution treatment (group SB-A) significantly improved the non-cast Ti-porcelain bond strength to $34.60 \mathrm{MPa}$, which was about 1.4 times higher than the minimum value (25 MPa) specified in ISO 9693. The bond strength between the non-cast $\mathrm{Ti}$ and porcelain was related to not only the Ti surface topography but also the Ti surface chemistry.

\section{CONCLUSION}

The $\mathrm{Ti}$ surfaces treated with an $\mathrm{HNO}_{3}$-containing acid solution after sandblasting treatment showed a significantly improved Ti-porcelain bond strength $(34.60 \pm 1.79 \mathrm{MPa})$ compared with the Ti surfaces that were only sandblasted $(29.63 \pm 1.14 \mathrm{MPa})$. However, the sandblasted Ti surfaces treated with a caustic alkaline solution or caustic alkaline solution followed by acid solution did not show significant difference with regard to the Ti-porcelain bond strength. Regardless of the surface treatments used for non-cast Ti, the fracture mode of all test Ti-porcelain specimens after the threepoint bending tests was of the adhesive type, and the bond strengths of all test Ti-porcelain specimens were higher than the minimum value $(25 \mathrm{MPa})$ specified in ISO 9693.

The bond strength between the porcelain and the ground non-cast Ti surface, which simulates the CAD/ CAM-produced conditions, can be significantly increased by applying the mechanical sandblasting treatment followed by the chemical acid treatment to the Ti surface prior to porcelain sintering. This simple and practical surface treatment procedure is provided as a reference for clinical practice in the dental laboratory.

\section{ACKNOWLEDGMENTS}

The authors would like to thank the National Science Council (Grant No. NSC 97-2314-B-166-002-MY3), Southern Taiwan Science Park Administration (AZ-1518-01-99) and Taipei City Hospital (Grant No. 9700262-046), Taiwan, for financial support. Thanks are also due to Prof. Hsueh-Chuan Hsu and Mr. Cheng-Wei Lin, 
Central Taiwan University of Science and Technology, Taiwan, for their assistance with the bending test.

\section{REFERENCES}

1) Kimura H, Horng CJ, Okazaki M, Takahashi J. Oxidation effects on porcelain-titanium interface reactions and bond strength. Dent Mater J 1990; 9: 91-99.

2) Wang RR, Fung KK. Oxidation behavior of surface-modified titanium for titanium-ceramic restorations. J Prosthet Dent 1997; 77: 423-434.

3) Adachi M, Mackert JR, Parry EE, Fairhurst CW. Oxide adherence and porcelain bonding to titanium and Ti-6Al-4V alloy. J Dent Res 1990; 69: 1230-1235.

4) Pang IC, Gilbert JL, Lautenschlager EP, Chai JY. Bonding characteristics of low-fusing porcelain to titanium and palladium-copper alloy. Northwest Dent Res 1994; 4: 15-16.

5) International Organization for Standardization. Metalceramic dental restorative systems: ISO 9693. ISO, 1999.

6) Sadeq A, Cai Z, Woody RD, Miller AW. Effects of interfacial variables on ceramic adherence to cast and machined commercially pure titanium. J Prosthet Dent 2003; 90: 1017.

7) Tróia Jr. MG, Henriques GE, Nóbilo MA, Mesquita MF. The effect of thermal cycling on the bond strength of low-fusing porcelain to commercially pure titanium and titaniumaluminium-vanadium alloy. Dent Mater 2003; 19: 790-796.

8) Reyes MJ, Oshida Y, Andres CJ, Barco T, Hovijitra S, Brown D. Titanium-porcelain system. Part III: effects of surface modification on bond strengths. Biomed Mater Eng 2001; 11: 117-136.

9) Suansuwan N, Swain MV. Adhesion of porcelain to titanium and a titanium alloy. J Dent 2003; 31: 509-518.

10) Fernandes Neto AJ, Panzeri H, Neves FD, Do Prado RA, Mendonça G. Bond strength of three dental porcelains to NiCr and Co-Cr-Ti alloys. Braz Dent J 2006; 17: 24-28.

11) İnan Ö, Acar A, Halkaci S. Effects of sandblasting and electrical discharge machining on porcelain adherence to cast and machined commercially pure titanium. J Biomed Mater Res B Appl Biomater 2006; 78: 393-400.

12) Tróia MG Jr, Henriques GE, Mesquita MF, Fragoso WS. The effect of surface modifications on titanium to enable titaniumporcelain bonding. Dent Mater 2008; 24: 28-33.

13) Guo LT, Liu XC, He ZY, Zhang H, Gao JQ, Yang JF, Guo TW. Surface modifications to improve Ti-porcelain bonding. J Mater Sci 2009; 44: 502-509.

14) Papadopoulos TD, Spyropoulos KD. The effect of a ceramic coating on the cpTi-porcelain bond strength. Dent Mater 2009; 25: 247-253.

15) Guo LT, Liu XC, Zhu YB, Xu C, Gao JQ, Guo TW. Effect of oxidation and $\mathrm{SiO}_{2}$ coating on the bonding strength of TiPorcelain. J Mater Eng Perform 2010; 19: 1189-1192.

16) Li JX, Zhang YM, Han Y, Zhao YM. Effects of micro-arc oxidation on bond strength of titanium to porcelain. Surf Coat Technol 2010; 204: 1252-1258.

17) Wang SS, Xia Y, Zhang LB, Guang HB, Shen M, Zhang FM. Effect of $\mathrm{NbN}$ and $\mathrm{ZrN}$ films formed by magnetron sputtering on Ti and porcelain bonding. Surf Coat Technol 2010; 205: 1886-1891.

18) Xia Y, Zhou S, Zhang F, Gu N. Effect of ZrN coating by magnetron sputtering and sol-gel processed silica coating on titanium/porcelain interface bond strength. J Mater Sci Mater Med 2011; 22: 317-325.
19) Bienias J, Surowska B, Stoch A, Matraszek H, Walczak M. The influence of $\mathrm{SiO}_{2}$ and $\mathrm{SiO}_{2}-\mathrm{TiO}_{2}$ intermediate coatings on bond strength of titanium and Ti6Al4V alloy to dental porcelain. Dent Mater 2009; 25: 1128-1135.

20) Könönen M, Kivilahti J. Bonding of low-fusing dental porcelain to commercially pure titanium. J Biomed Mater Res 1994; 28: 1027-1035.

21) Speelman JA, Collaert B, Klinge B. Evaluation of different methods to clean titanium abutments. A scanning electron microscopic study. Clin Oral Implants Res 1992; 3: 120-127.

22) Diniz MG, Pinheiro MA, Andrade AC Jr, Fischer RG. Characterization of titanium surfaces for dental implants with inorganic contaminant. Braz Oral Res 2005; 19: 106111.

23) Cai Z, Bunce N, Nunn ME, Okabe T. Porcelain adherence to dental cast CP titanium: effects of surface modifications. Biomaterials 2001; 22: 979-986.

24) Boettinger WJ, Williams ME, Coriell SR, Kattner UR, Müller BA. Alpha case thickness modeling in investment castings. Metall Mater Trans B 2000; 31: 1419-1427.

25) Sung SY, Kim YJ. Alpha-case formation mechanism on titanium investment castings. Mater Sci Eng A 2005; 405: 173-177.

26) Say WC, Tsai YY. Surface characterization of cast Ti-6Al-4V in hydrofluoric-nitric pickling solutions. Surf Coat Technol 2004; 176: 337-343.

27) Besimo C, Jeger C, Guggenheim R. Marginal adaptation of titanium frameworks produced by $\mathrm{CAD} / \mathrm{CAM}$ techniques. Int J Prosthodont 1997; 10: 541-546.

28) Taira Y, Matsumura H, Yoshida K, Tanaka T, Atsuta M. Influence of surface oxidation of titanium on adhesion. J Dent 1998; 26: 69-73.

29) Witkowski S, Komine F, Gerds T. Marginal accuracy of titanium copings fabricated by casting and CAD/CAM techniques. J Prosthet Dent 2006; 96: 47-52.

30) Tan PL, Gratton DG, Diaz-Arnold AM, Holmes DC. An in vitro comparison of vertical marginal gaps of $\mathrm{CAD} / \mathrm{CAM}$ titanium and conventional cast restorations. J Prosthodont 2008; 17: 378-383.

31) King AW, Chai J, Lautenschlager E, Gilbert J. The mechanical properties of milled and cast titanium for ceramic veneering. Int J Prosthodont 1994; 7: 532-537.

32) Gilbert JL, Covey DA, Lautenschlager EP. Bond characteristics of porcelain fused to milled titanium. Dent Mater 1994; 10: 134-140.

33) Boeckler AE, Lee H, Stadler A, Setz JM. Prospective observation of CAD/CAM titanium ceramic single crowns: a three-year follow up. J Prosthet Dent 2009; 102: 290-297.

34) Guha A. In: Murray JL, editor. ASM Metals Handbook volume 8: mechanical testing and evaluation. 9th ed. Metals Park: ASM International; 1985. p. 132-136.

35) Papadopoulos T, Tsetsekou A, Eliades G. Effect of aluminium oxide sandblasting on cast commercially pure titanium surfaces. Eur J Prosthodont Rest Dent 2003; 7: 15-21.

36) Hussaini AI, Wazzan KA. Effect of surface treatment on bond strength of low-fusing porcelain to commercially pure titanium. J Prosthet Dent 2005; 94: 350-356.

37) Yan M, Kao CT, Ye JS, Huang TH, Ding SJ. Effect of preoxidation of titanium on the titanium-ceramic bonding. Surf Coat Technol 2007; 202: 288-293.

38) Zinelis S, Barmpagadaki X, Vergos V, Chakmakchi M, Eliades G. Bond strength and interfacial characterization of eight low fusing porcelains to cp Ti. Dent Mater 2010; 26: 264-273. 